\title{
SISTEM PENDUKUNG KEPUTUSAN MENGGUNAKAN SIMPLE ADDITIVE WEIGHTING DALAM PEMBERIAN REWARD KARYAWAN
}

\author{
Marfuah $^{1)}$, Steffi Adam ${ }^{2)}$ \\ 12 Universitas Universal Batam \\ marfuah916@gmail.com, steffiadam.ssi@gmail.com
}

\begin{abstract}
Rewards can increase morale for employees to continue to provide better performance. Employees who have good performance can be categorized as exemplary employees. At PT. XYZ, which is located in the city of Batam, so far in making decisions related to giving rewords has not been supported by a computerized system. In the assessment process carried out there are several criteria used to give rewards to employees. To support the subjective assessment of the company towards its employees, it is very important to use a decision support system using the simple additive weighing (SAW) method. The use of this method by giving weight to the criteria used. The criteria used are transaction targets, absences and leave. Based on the existing criteria and alternatives, after weighting and calculations, the top 3 rankings in giving rewords are $v 7$ with a value of 5.5, v1 with a value of 5.3 and $v 8$ with a value of 5.
\end{abstract}

Keyword : Reword, Decision Support System, Simple Additive Weighting.

\begin{abstract}
Abstrak
Reward dapat meningkatkan semangat kerja bagi para karyawan untuk terus memberikan kinerja yang lebih baik. Sehingga para karyawan yang memiliki kinerja yang baik dapat di kategorikan sebagai karyawan teladan. Pada PT. XYZ yang berada di kota Batam, selama ini dalam pengambilan keputusan terkait pemberian reword belum didukung dengan suatu sistem yang terkomputerisasi. Sedangkan dalam proses penilaian tersebut terdapat beberapa kriteria yang digunakan untuk pemberian reword kepada karyawan. Sehingga, untuk mendukung penilain yang subjektif dari perusahaan terhadap karyawan maka, sangat penting menggunakan sistem pendukung keputusan dengan menggunakan metode simple additive weigting $(S A W)$. Penggunaan metode tersebut dengan memberikan pembobotan terhadap kriteria yang digunakan. Adapun kriteria yang digunakan yaitu target transaksi, absen dan pengambilan cuti. Berdasarkan kriteria dan alternatif yang ada, setelah dilakukan pembobotan dan perhitungan didapatkan 3 rengking teratas dalam pemberian reword yaitu v7 nilai 5,5, v1 nilai 5,3 dan v8 dengan nilai 5.
\end{abstract}

Kata Kunci : Reward, Sistem Pendukung Keputusan, Simple Additive Weighting. 


\section{PENDAHULUAN}

Seiring terjadinya perubahan yang begitu cepat mendorong perkembangan teknologi semakin pesat [1]. Sehingga pemanfaatan teknologi sudah menjadi suatu keharusan terutama di era pandemi yang masih berlangsung hingga kini [2]. Revolusi industy 4.0 menyederhanakan proses bisnis secara digital [3].

PT. xyz berdiri sejak 2010, di Batam. Perusahaan ini bergerak di bidang jasa transaksi-transaksi tunai seperti tagihan TV kabel, listrik, air, multifinance, asuransi dan telepon. Perusahan juga memiliki program reword untuk memotivasi para karyawan agar terus meningkatkan kinerja nya. Hal ini dilakukan untuk menentukan karyawan terbaik dan berkualitas, mengingat karyawan adalah asset yang sangat berharga. Asset ini dapat membawa perubahan keberlangsungan hidup perusahaan [4]. Untuk menghindari bobot penilaian yang subjektif maka, perlu adanya sistem pendukung keputusan untuk pemberian reword karyawan. Sistem pendukung keputusan didesain sederhana agar mudah digunakan oleh user yang hanya mempunyai kemampuan dasar pengoperasian computer [5]. Metode simple additive weighting merupakan salah satu metode yang digunakan untuk perengkingan [6].

Penerapan sistem pendukung keputusan menggunakan metode SAW sudah banyak digunakan, diantaranya yaitu penelitian [7] dalam pemberian reword bagi pegawai honorer. Hasil dari penelitian ini dapat memberikan hasil perengkingan yang objektif.
Penelitian selanjutnya dilakukan oleh [8] mengenai penentuan karyawan teladan menggunakan metode SAW. Proses penilaian dengan melibatkan beberapa kriteria yang digunakan. Hasil penelitian diperoleh bahwa sistem dapat memberikan kemudahan dalam menentukan karyawan terbaik.

Berdasarkan hal tersebut bahwa, dalam pemberian reword karyawan yang dilakukan pada PT. xyz juga menggunakan beberapa kriteria yaitu target transaksi, absen dan pengambilan cuti. Oleh sebab itu metode yang digunakan dalam penelitian ini yaitu SAW dengan melakukan pembobotan kriteria dan proses perhitungan yang bertujuan untuk memberikan hasil yang objektif.

\section{METODE}

\subsection{Tahapan Penelitian}

Adapun tahapan penelitian yang dilakukan, sebagaimana gambar 1 .

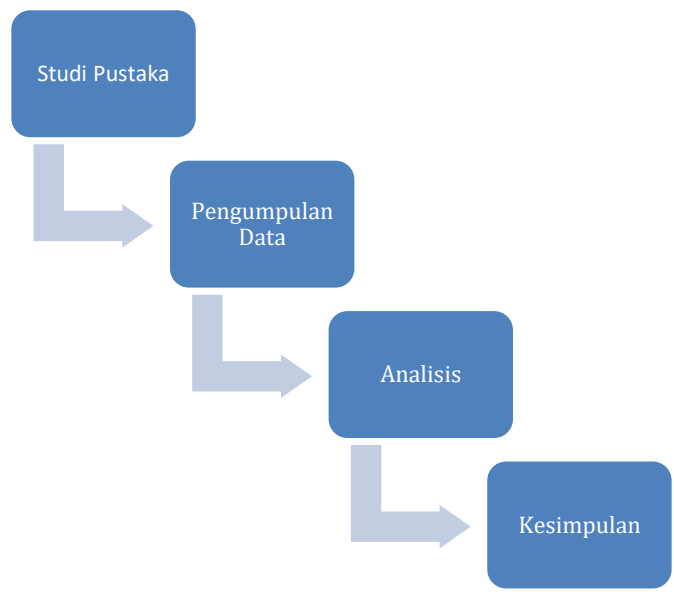

Gambar 1. Tahapan Penelitian [7][9][10] 
Berdasarkan gambar 1 dapat dijelaskan bahwa tahapan penelitian yang dilakukan yaitu :

1. Studi Pustaka : Melakukan pengumpulan studi literatur terutama bersumber pada penelitian terdahulu yang berkaitan dengan reword dan metode SAW.

2. Pengumpulan Data : Melakukan pengumpulan data yang bersumber dari pimpinan PT. xyz dan mempelajari data-data yang didapatkan. Terutama kriteria yang digunakan dalam pemberian reword terhadap karyawan.

3. Analisis : Melakukan analisis data menggunakan metode SAW.

4. Kesimpulan : Hasil pemberian reword terhadap karyawan PT. xyz menggunakan metode SAW.

\subsection{Simple Additive Weghting (SAW)}

Adapun prosedur yang harus dilakukan dalam metode SAW sebagaimana gambar 2 .

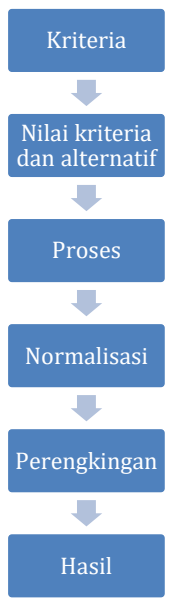

Gambar 2. Prosedur SAW [11]

Sebagai Langkah awal yaitu menentukan kriteria yang telah didapatkan dalam pengumpulan data [12]. Sebagaimana tabel 1.

Table 1. Kriteria

\begin{tabular}{|l|l|l|}
\hline Kriteria & Keterangan & Jenis \\
\hline C1 & Target Transaksi & Benefit \\
\hline C2 & Absen & Cost \\
\hline C3 & Pengambilan Cuti & Cost \\
\hline
\end{tabular}

Nilai w berdasarkan kriteria yaitu c1 nilai 3, c2 nilai 2 dan c3 nilai 1 . Adapun sub kriteria dari masing-masing kriteria sebagaimana tabel 2, 3 dan 4 .

Tabel 2. Sub Kriteria Target Transaksi

\begin{tabular}{|l|l|}
\cline { 2 - 2 } \multicolumn{1}{c|}{} & $c 1$ \\
\hline 1 & $<50$ hari \\
\hline 2 & $>=50$ dan $<100$ hari \\
\hline 3 & $>=100$ \\
\hline
\end{tabular}

Tabel 3. Sub Kriteria Absen

\begin{tabular}{|l|l|}
\cline { 2 - 2 } \multicolumn{1}{c|}{} & \multicolumn{1}{c|}{} \\
\hline 1 & $<5$ hari \\
\hline 2 & $>=5$ dan $<10$ hari \\
\hline 3 & $>=10$ hari \\
\hline
\end{tabular}

Tabel 4. Sub Kriteria Pengambilan Cuti

\begin{tabular}{|l|l|}
\cline { 2 - 2 } \multicolumn{1}{l|}{} & c3 \\
\hline 1 & $<6$ hari \\
\hline 2 & $>=6$ dan $<12$ hari \\
\hline 3 & $>=12$ hari \\
\hline
\end{tabular}

Persamaan yang digunakan untuk normalisasi matrik. Sebagaimana ditunjukkan pada persamaan (1) dan (2) [13].

$$
r i j=\frac{x i j}{\max (x i j)}
$$




$$
r i j=\frac{\min (x i j)}{x i j}
$$

Keterangan [11]:

rij : : Rating kinerja ternormalisasi

$\max \quad$ : Bobot maksimum kriteria

min : Bobot minimum kriteria

xij : Nilai atribut masing-masing kriteria yang terdapat pada baris dan kolom dari matriks

Benefit : Nilai terbesar yang terbaik

Cost : Nilai terkecil yang terbaik

Langkah selanjutnya melakukan normalisasi matrik X menjadi matrik $\mathrm{R}$. Sebagaimana ditunjukkan pada persamaan (3).

$$
r i j=\frac{c 1}{c 1+\cdots+c n} \times 100 \%
$$

Kemudian proses perengkingan menggunakan persamaan (4) [14][15].

$$
V i=\sum_{j-1}^{n}=1 w j r i j
$$

Keterangan:

$v i$ : Nilai akhir alternatif

$w j$ : bobot ranking

\section{KERANGKA TEORI}

3.1 Sistem Pendukung Keputusan

Sistem pendukung keputusan dapat diartikan sebagai sistem berbasis komputer yang memberikan altenatif solusi terhadap masalah semi terstruktur dan tidak terstruktur yang dihadapi. [6][16]. Walau ada kemungkinan tidak ditemukannya solusi terbaik, akan tetapi sistem pendukung keputusan dapat memberikan stimulan kepada pimpinan atau user agar dapat memahami permasalahan yang dihadapi [8].

Adapun tujuan dari sistem pendukung keputusan ini yaitu [8]:

1. Membantu pimpinan atau user dalam membuat keputusan terkait solusi terhadap permasalahan yang dihadapi

2. Mendukung penilaian yang diberikan oleh pimpinan atau user

3. Meningkatkan efektivitas pengambilan keputusan

Sehingga dalam menggunakan sistem pendukung keputusan terdapat beberapa keuntungan yang dapat diperoleh yaitu [8]:

1. Meningkatkan kemampuan proses data atau informasi dalam pengambil keputusan

2. Mampu memecahkan masalah yang sangat kompleks.

3. Proses mendapatkan alternatif solusi yang lebih cepat dan dapat diandalkan.

\subsection{Reword Karyawan}

Aset penting dari sebuah perusahaan salah satunya yaitu karyawan yang dimiliki [8]. Karyawan harus benar-benar dikelola dengan baik, salah satunya yaitu dengan cara pemberian reword terhadap para karyawan teladan yang dimiliki [17]. Hal ini dilakukan untuk mendorong para karyawan agar terus meningkatkan kinerjanya [18]. Reward merupakan 
apresiasi atas prestasi yang didapat bisa berbentuk materi atau non-materi [19].

\section{PEMBAHASAN}

Adapun penerapan metode SAW dalam penelitian ini, sebagaimana tabel 5 berdasarkan data yang diperoleh.

Tabel 5. Data yang dinilai

\begin{tabular}{|c|c|c|c|}
\hline \multirow{2}{*}{ alternatif } & \multicolumn{3}{|c|}{ kriteria } \\
\cline { 2 - 4 } & c1 & c2 & c3 \\
\hline a1 & 102 & 2 & 12 \\
\hline a2 & 88 & 8 & 0 \\
\hline a3 & 30 & 13 & 0 \\
\hline a4 & 102 & 10 & 13 \\
\hline a5 & 77 & 1 & 7 \\
\hline a6 & 150 & 11 & 8 \\
\hline a7 & 100 & 0 & 11 \\
\hline a8 & 45 & 3 & 2 \\
\hline a9 & 25 & 0 & 1 \\
\hline a10 & 150 & 10 & 8 \\
\hline
\end{tabular}

Langkah selanjutnya yaitu membentuk matrik keputusan $\mathrm{x}$, sebagaimana tabel 6 .

Tabel 6. Matrik Keputusan X

$X=$\begin{tabular}{|c|c|c|c|}
\hline 1 & 2 & 3 & \multicolumn{1}{|c|}{} \\
\hline 3 & 1 & 3 & 1 \\
\hline 2 & 2 & 1 & 2 \\
\hline 1 & 3 & 1 & 3 \\
\hline 3 & 3 & 3 & 4 \\
\hline 2 & 1 & 2 & 5 \\
\hline 3 & 3 & 1 & 6 \\
\hline 3 & 1 & 2 & 7 \\
\hline 2 & 1 & 1 & 8 \\
\hline 1 & 1 & 1 & 9 \\
\hline 3 & 3 & 2 & 10 \\
\hline
\end{tabular}

Kemudian

melakukan normalisasi matrik menggunakan persamaan (1) dan (2), hasil sebagaimana terlihat pada tabel 7 .

Tabel 7. Menormalisasi matriks X menjadi matriks R C1)

\begin{tabular}{|c|c|c|c|}
\hline $\mathrm{r} 1=$ & 1,0 & 1,0 & 0,3 \\
\hline $\mathrm{r} 2=$ & 0,7 & 0,5 & 1,0 \\
\hline $\mathrm{r} 3=$ & 0,3 & 0,3 & 1,0 \\
\hline $\mathrm{r} 4=$ & 1,0 & 0,3 & 0,3 \\
\hline $\mathrm{r} 5=$ & 0,7 & 1,0 & 0,5 \\
\hline $\mathrm{r} 6=$ & 1,0 & 0,3 & 1,0 \\
\hline $\mathrm{r} 7=$ & 1,0 & 1,0 & 0,5 \\
\hline $\mathrm{r} 8=$ & 0,7 & 1,0 & 1,0 \\
\hline $\mathrm{r} 9=$ & 0,3 & 1,0 & 1,0 \\
\hline $\mathrm{r} 10=$ & 1,0 & 0,3 & 0,5 \\
\hline
\end{tabular}

Langkah selanjutnya yaitu proses perengkingan, sebagaimana terlihat pada tabel 8 .

Tabel 8. Proses Perengkingan

\begin{tabular}{|l|c|c|c|c|}
\cline { 2 - 4 } \multicolumn{1}{l|}{} & 1 & 2 & 3 & \multicolumn{1}{c}{} \\
\hline $\mathrm{v} 1=$ & 3 & 2 & 0,3 & $\mathbf{5 , 3}$ \\
\hline $\mathrm{v} 2=$ & 2 & 1 & 0,3 & 3,3 \\
\hline $\mathrm{v} 3=$ & 1 & 0,7 & 1 & 2,7 \\
\hline $\mathrm{v} 4=$ & 3 & 0,7 & 0,3 & 4 \\
\hline $\mathrm{v} 5=$ & 2 & 2 & 0,5 & 4,5 \\
\hline $\mathrm{v} 6=$ & 3 & 0,7 & 1 & 4,7 \\
\hline $\mathrm{v} 7=$ & 3 & 2 & 0,5 & $\mathbf{5 , 5}$ \\
\hline $\mathrm{v} 8=$ & 2 & 2 & 1 & $\mathbf{5}$ \\
\hline $\mathrm{v} 9=$ & 1 & 2 & 1 & 4 \\
\hline $\mathrm{v} 10=$ & 3 & 0,7 & 0,5 & 4,2 \\
\hline
\end{tabular}

Hasil perengkingan berdasarkan tabel 8 diperoleh 3 peringkat teratas yaitu posisi satu v7 nilai 5,5, posisi dua v1 nilai 5,3 dan posisi tiga v8 nilai 5 . 


\section{PENUTUP}

Kesimpulan yang didapat dalam penelitian ini yaitu metode SAW menjadikan proses pemberian reword terhadap karyawan menjadi lebih efektif dan objektif. Hasil dalam penelitian ini didapat tiga alternatif terbaik yaitu v7 nilai 5,5, v1 nilai 5,3 dan v8 nilai 5. 


\section{REFERENCE}

[1] D. Setiawan, "Dampak Perkembangan Teknologi Informasi dan Komunikasi Terhadap Budaya," J. SIMBOLIKA Res. Learn. Commun. Study, vol. 4, no. 1, hal. 62, 2018, doi: 10.31289/simbollika.v4i1.1474.

[2] M. Fani dan I. A. Lestari, "Sistem online recruitment berbasis web pada PT. XYZ menggunakan metode Simple Additive Weighting (SAW)," 9th Appl. Bus. Eng. Conf., vol. 9, hal. 176-191, 2021, [Daring]. Tersedia pada: https://abecindonesia.org/proceeding/index.php/abec/article/view/156.

[3] C. Sundari, "Revolusi Industri 4.0 Merupakan Peluang Dan Tantangan Bisnis Bagi Generasi Milenial Di Indonesia," Pros. Semin. Nas. DAN CALL Pap., no. Fintech dan E-Commerce untuk Mendorong Pertumbuhan UMKM dan Industri Kreatif, hal. 555-563, 2019.

[4] R. Taufiq, A. Hambali, dan A. Saifudin, "Rancang Bangun Sistem Pendukung Keputusan Penilaian Karyawan Terbaik Pada PT. Surya Toto Indonesia, Tbk Menggunakan Metode Simple Additive Weighting (SAW) Berbasis WEB," J. Inform. Univ. Pamulang, vol. 6, no. 1, hal. 188, 2021, doi: 10.32493/informatika.v6i1.9836.

[5] R. Umar, A. Fadlil, dan Y. Yuminah, "Sistem Pendukung Keputusan dengan Metode AHP untuk Penilaian Kompetensi Soft Skill Karyawan," Khazanah Inform. J. Ilmu Komput. dan Inform., vol. 4, no. 1, hal. 27, 2018, doi: 10.23917/khif.v4i1.5978.

[6] N. Evani dan R. Rosalina, "KARYAWAN TERBAIK DENGAN METODE SIMPLE ADDITIVE WEIGHTING ( SAW ) DI PT .,” vol. 7, no. 2, hal. 130-144, 2021.

[7] T. Panggabean dan Y. F. Manalu, "Penerapan Metode Simple Additive Weighting ( SAW J dalam Pemberian Reward Bagi Pegawai Honorer Menggunakan Pembobotan Rank Order Centroid," vol. 5, hal. 1667-1673, 2021, doi: 10.30865/mib.v5i4.3146.

[8] G. Damayanti, sinta devi., "SISTEM PENDUKUNG KEPUTUSAN PENENTUAN KARYAWAN TELADAN DENGAN MENGGUNAKAN METODE SIMPLE ADDITIVE WEIGHTING (SAW)," Sist. Inf. dan Tek. Komput., vol. 6, no. 2, hal. 114-121, 2021.

[9] D. Cahyana, E. Martantoh, P. Studi, S. Informasi, dan U. P. Sakti, "Sistem Pendukung Pengambilan Keputusan Karyawan Terbaik Menggunakan Metode Simple Additive Weighting ( SAW ) Pada PT Nippon Indosari Corpindo Tbk Plant Cibitung," vol. 2, no. 2, hal. 265-276, 2021.

[10] V. Sihombing, V. M. M. Siregar, W. S. Tampubolon, M. Jannah, Risdalina, dan A. Hakim, "Implementation of simple additive weighting algorithm in decision support system," IOP Conf. Ser. Mater. Sci. Eng., vol. 1088, no. 1, hal. 012014, 2021, doi: 10.1088/1757-899x/1088/1/012014.

[11] L. Febriantahanuji., Nanik, "SIMPLE ADDITIVE WEIGHTING UNTUK PENENTUAN PEMBERIAN INSENTIF KEPADA KARYAWAN TERBAIK DI PT. CAMPUS DATA MEDIA BERBASIS WEB MVC," Akunt. dan bisnis, vol. 1, no. 1, hal. 30-41, 2021. 
[12] N. Hazimah, S. Harahap, dan A. Zahraini, "Laptop selection decision support system according to buyer criteria with the simple additive weighting method," hal. 127-134, 2021.

[13] I. J. T. Situmeang, S. Hummairoh, S. M. Harahap, dan M. Mesran, "Application of SAW (Simple Additive Weighting) for the Selection of Campus Ambassadors," IJICS (International J. Informatics Comput. Sci., vol. 5, no. 1, hal. 21-28, 2021, doi: 10.30865/ijics.v5i1.2847.

[14] B. Purba, Y. Wibisono, R. Sihotang, A. Thofiq, dan S. Hasibuan, "Penerapan Metode Simple Additive Weighting ( SAW ) Dalam Rekomendasi Perpanjangan Kontrak Kerja Pada PT PDAM Tirtanadi Cabang Medan Kota," hal. 222-227, 2021.

[15] F. P. Hutagaol dan J. H. Lubis, "Bulletin of Information Technology ( BIT ) Penerapan Metode Simple Additive Weighting ( SAW ) dalam Pemilihan Handphone Bekas," vol. 2, no. 2, hal. 63-68, 2021.

[16] M. Rizky, R.M., M.Khairul, N., "Penerapan Metode SAW (Simple Additive Weighting) Dalam Pemilihan Siswa-Siswi Berprestasi Pada Sekolah SMK Swasta Mustafa," Terap. Inform. Nusant., vol. 1, no. 9, hal. 459-471, 2021.

[17] P. P. A. P. Indah, P. I. Rahmawati, dan N. D. Andiani, "Pengaruh Sistem Penghargaan (Reward) Terhadap Kinerja Trainee Di Hotel Holiday Inn Resort Baruna Bali," J. Manaj. Perhotelan dan Pariwisata, vol. 2, no. 1, hal. 41, 2019, doi: 10.23887/jmpp.v2i1.22087.

[18] A. Wirawan dan I. N. Afani, "Pengaruh Reward Dan Punishment Terhadap Kinerja Dan Motivasi Karyawan Pada Cv Media Kreasi Bangsa," J. Appl. Bus. Adm., vol. 2, no. 2, hal. 242-257, 2018, doi: 10.30871/jaba.v2i2.1124.

[19] R. A. Pramesti, S. A. P. Sambul, dan W. Rumawas, "Pengaruh Reward Dan Punishment Terhadap Kinerja Karyawan KFC Artha Gading," J. Adm. Bisnis, vol. 9, no. 1, hal. 57, 2019, doi: 10.35797/jab.9.1.2019.23557.57-63. 